Celestinesca 3I (2007): 103-118 https://doi.org/10.7203/Celestinesca.31.20072

\title{
Fernando de Rojas: el lector desvelado (en su caligrafía). De nuevo sobre el «In- ventario» de sus libros
}

\author{
Víctor Infantes \\ Universidad Complutense
}

Quaerendo invenietis

Scholiae de Juan Sebastián

Bach en su Ofrenda musical.

Hace ahora diez años que publiqué un extenso trabajo sobre al «Inventario» de los libros de Fernando de Rojas, ${ }^{1}$ concretamente sobre sus libros «de romance» - que vale tanto, para entendernos, como decir «literatura»-, distinguiendo con la aposición los libros «de leyes», muchos de ellos en latín, por más que ambos formaban parte de la biblioteca del que fue Alcalde de Talavera de la Reina. Dicho «Inventario», incluido en la relación de los bienes de su Testamento, vio la luz crítica en 1929 gracias a la generosidad de su propietario, Don Fernando del Valle Lersundi, heredero de la familia Rojas, que puso a disposición de todos los interesados en las páginas de la Revista de Filología Española los documentos de las últimas voluntades de Rojas, otorgado en la villa toledana el 3 de abril de $1541 .^{2}$ Me interesaba entonces (y me sigue interesando todavía)

1.- Víctor Infantes, "Los libros «traydos y viejos y algunos rotos» que tuvo el Bachiller Fernando de Rojas, nombrado autor de la obra llamada Celestina», Bulletin Hispanique [Lisant et Lecteurs en Espagne XV'-XIXe siècle], 100.2 (1998), pp. 7-51. (Quede en la primera nota mi agradecimiento a Juan Carlos Conde, lector previo de este trabajo, a cuya amistad y saber debo correcciones de peso y enjundia.)

2.- Fernando del Valle Lersundi, "Testamento de Fernando de Rojas, autor de La Celestina», Revista de Filología Española, XVI (1929), pp. 365-388; pocos años antes había publicado también unos interesantísimos "Documentos referentes a Fernando de Rojas», Revista de Filología Española, XI (1925), pp. 385-396. 
el análisis en detalle todos los datos relativos a la posible identificación de los volúmenes que Rojas poseyó, pero con el marcado interés en acercarme todo lo más posible - es decir, todo lo más posible que permitían los asépticos datos del documento- a la edición que en concreto pudo haber tenido en sus manos el Bachiller. Si me extendí en numerosas aclaraciones, si escarbé los silenciosos testimonios menudos de la transcripción y si me emplazaba casi de continuo en sugerencias e hipótesis de difícil comprobación, no quería con ello más que intentar contestar las incógnitas que plantean cualquier documento y, muy más especialmente, por indagar que podría aportarnos para un mejor entendimiento de la $\mathrm{Ce}$ lestina la pertenencia de aquella media centena de libros «traydos, viejos y algunos rotos». ${ }^{3}$ Escasas meas culpas debo añadir un decenio después sobre la identificación de los libros y menos todavía sobre las conclusiones de aquel análisis, que - como dije- nos acercaba muy fehacientemente «a su mundo cultural y personal, pero nos ayuda[ba] bien poco a entender esa obra llamada Celestina». La oportunidad de una próxima reedición de aquel estudio, ${ }^{4}$ sumado ahora con otro sobre las primitivas ediciones de la Comedia y Tragicomedia de Calisto y Melibea, ${ }^{5}$ me ha hecho volver a las carpetas e intentar desclavar las dos espinas que entonces se quedaron prendidas entre los propósitos: ver los documentos originales y comprobar la posible existencia de algún ejemplar que fuera de Fernando de Rojas.

Decíamos entonces a los dos respectos: ${ }^{6}$

El «Testamento» e «Inventario de bienes» de Fernando de Rojas lo tenemos que seguir necesariamente (de momento) a través de la transcripción que en su día realizó don Fernando del Valle Lersundi, descendiente del escritor y poseedor del documento original; así lo indica la localización catalográfica: «Archivo particular de Lersundi,

3.- Son en realidad 49 items, pero en el «Inventario» a la muerte de su esposa, Leonor Álvarez en 1546 se recogen otros 6 volúmenes (digamos también) literarios, alguno de los cuales con cierta seguridad pudieron ser asimismo de Rojas, pero que por las razones que fueran no se incluyeron en el «Inventario» de sus bienes cinco años antes; no obstante, también los analizamos y dimos las pertinentes aclaraciones sobre su identificación y su posible pertenencia al Bachiller, vid. V. Infantes, «Los libros», cit, pp. 41-44.

4.- Deberá aparecer en la Biblioteca Litterae, gracias a los desvelos y al interés de Emilio Torné.

5.- Vid. Víctor Infantes, «El laberinto cronológico y editorial de las primitivas impresiones de Celestina (1497-1514). Con una Marginalia bibliographica al cabo», en Actas del Simposio Internacional 1502-2002: Five Hundred Years of Fernando de Rojas' Tragicomedia de Calisto y Melibea (18-19 de octubre de 2002, Departamento de Español y Portugués, Indiana University, Bloomington), ed. Juan Carlos Conde, New York, Hispanic Seminary of Medieval Studies, 2007, pp. 3-87.

6.- V. Infantes, «Testamento», cit., p. 10, p. 12 y p. 51, respectivamente. 
Mayorazgo de Rojas, legajo núm. 3, documento 23», hoy por hoy no está asequible la consulta al investigador.

y concluíamos respecto a los libros:

Es obvio que en un trabajo como el presente contamos con los datos que hoy poseemos de las ediciones de cada obra, lo que no reduce en absoluto la posibilidad de que Rojas tuviera ediciones de las que hoy no sospechamos ni su simple existencia, es más, estamos convencidos de ello; no obstante, las obras en sí están prácticamente todas identificadas y las precisiones editoriales en general, también; no parece entonces que alguna sorpresa cambie el panorama general de la biblioteca de Rojas, dado el breve espacio cronológico en que nos desenvolvemos. (Recordamos que al menos en los años setenta todavía parece que se conservaban en el Archivo de la familia Valle Lersundi en Deva algunos ejemplares de Rojas, Gilman así lo afirma: «aquella biblioteca formada a lo largo de generaciones (contiene, de hecho, algunos libros que pertenecieron a Rojas)», ${ }^{7} \mathrm{y}$ "los pocos libros que aún siguen en posesión de su descendiente directo, don Fernando del Valle Lersundi», aunque de momento no ha sido posible la consulta de los mismos por nuestra parte.)

añadíendo como remate:

Las gestiones emprendidas por nuestra parte para ver el documento original, y los libros de Rojas que se puedan conservar, o al menos se conservaban en los años setenta, van por el buen camino de la esperanza, aunque no confirmada a la hora de terminar el trabajo; pero esperamos algún día cotejarlo y ver los ejemplares que tantas horas han robado a nuestros afanes.

Las dos heridas críticas están empezando a cauterizar. Vayamos con la primera.

El Testamento de Fernando de Rojas estuvo en nuestras manos hace unos pocos días, gracias a la generosidad de sus propietarios actuales, los herederos de Don Fernando del Valle Lersundi, ${ }^{8}$ junto al resto de documentos

7.- Vid. Stephen Gilman, La España de Fernando de Rojas. Panorama intelectual y social de La Celestina [1972], Madrid, Taurus, 1972, p. 15 y p. 440, a quien preferimos citar por la traducción española para facilitar las comprobaciones.

8.- Y es de ley agradecer sus atenciones y facilidades para ver, ipor fin!, el ansiado documento. Su generosidad se extendió a prestar el legajo para la exposición de El jardín de Melibea, Burgos, Sociedad Estatal para la Conmemoración de los Centenarios de Felipe II y Carlos v, 
pertenecientes al «Mayorazgo de Rojas» («Partición de bienes de la legítima paterna entre los hijos y la mujer», etc.); aunque de él, y para nuestra investigación actual, sólo nos interesa ahora lo relativo al "Inventario» de los libros. Efectivamente, como suponíamos y parecía deducirse de la transcripción de 1929, son dos documentos independientes; el Testamento en sí (Legajo $\mathrm{n}^{\circ} 2$, documento 17; folio, 6 hs., envuelto en guardas de testificación manuscrita de 1789) ${ }^{9}$ y la relación de los bienes del Bachi1ler. Este segundo documento (Legajo $n^{\circ}$ 3, documento 23; folio (227x309 $\mathrm{mm}$.), 1 h.+17 hs.) se puede titular "Inventario de los bienes», y así lo sugirió Fernando del Valle Lersundi, ${ }^{10}$ puesto que en el recto de la hoja de guarda, en letra y papel del siglo xviII, ${ }^{11}$ se lee antes del comienzo del texto

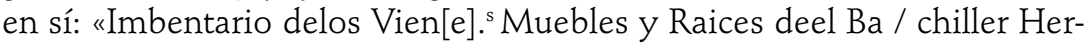
nando de Rojas vez[ino]. ${ }^{\circ}$ dela Villa de Talabera / echo ante la vi[11]..$^{a}$ della apedim[ien]. ${ }^{\text {to }}$ de $\mathrm{D}^{\mathrm{a}}$ Leonor Alvarez / Mug[e]. ${ }^{\mathrm{r}}$ de d[i]cho D. ${ }^{\mathrm{n}}$ Hernando; sehizo ante Juande are / valo, es[criba]. ${ }^{\text {no }}$ de S[u]. M[agestad]. Y publico de d[i]cha Villa.». A continuación (h. 1r) se inicia el «Inventario», en letra y papel del siglo XVI, ${ }^{12}$ que comienza: «En la noble Villa detalavera [...]»; $;^{13}$ tras la extensa nómina de propiedades del Bachiller, se llega, en las hs. 13 $\mathrm{v}-14 \mathrm{r}$, a sus [signación] «libros de romance».

La lista ocupa el vuelto de una hoja y el recto de la siguiente, aunque el encabezamiento de [signación] «libros de romance» nos parece

2000, donde se encuentra reproducida su primera página, p. 202, junto a las «Cuentas del enterramiento y funerales de Fernando de Rojas».

9.- Transcripción fiel de F. del Valle Lersundi, «Testamento», cit., pp. 366-370, con reproducción reducida de primera y última página, p. 367 y p. 371, respectivamente.

10.- F. del Valle Lersundi, «Testamento», cit., p. 371, entre corchetes, con transcripción completa, p. 317-383.

11.- En esta hoja se observa una diáfana marca de papel, claramente del siglo xviII, con las letras contorneadas: "MALLO»; no hemos localizado (todavía) al fabricante y no aparece en el tercer volumen de Oriol Valls i Subirá, Historia del papel en España. Siglos XVII-XIX, Madrid, Empresa Nacional de Celulosas, 1982, aunque en él, III, p. 313 se menciona un Molino de Mallada en Torrefarrera, provincia de Lérida, activo en 1766 y que tal vez pudiera relacionarse nominalmente, tampoco se recoge en Gonzalo Gayoso Carreira, Historia del papel en España, Lugo, Diputación Provincial, 1994, 3 ts. En cualquier caso, es (necesariamente) probable que sea de la misma época que la hoja de guarda del "Testamento", testificada en 1789.

12.- Tampoco están en O. Valls i Subirá, cit., ni en G. Gayoso Carreira, cit., las dos filigranas que aparecen en las hojas interiores del inventario, en el cuaderno de escribanía de las 16 primeras hojas una mano abierta con los cinco dedos separados, adorno picudo en el dorso y estrella pentagonal suspendida y en la hoja 17, que hace la función de segunda guarda, la misma mano, pero con adorno distinto en la misma posición del dorso, en este caso lobulado. Las dos clases de papel pertenecen, pues, al mismo fabricante, con una leve diferencia en la filigrana. Hay algunos similares, todos del siglo XVI, pero (desafortunadamente) ninguno igual, en el volumen tercero de Charles M., Briquet, Les filigranes. Dictionnaire historique des marques du papier, Leipzig, Karl W. Hiersemann, 1921², 4 vols. [= Hildesheim, Georg Olms, 1991].

13.- Transcripción fiel del contenido que sigue en F. del Valle Lersundi, «Testamento», cit., pp. 317-383. 
de otra mano, coetánea pero desde luego distinta ${ }^{14}$ de la que relaciona a continuación los títulos, que aparecen precedidos de una signación - generalmente con punto añadido, aunque no siempre-, a modo de comprobación de cada una de las entradas. Hemos corroborado la correcta transcripción de todos los items y resuelto (favorablemente) alguna duda, como la del $n^{\circ}[9]$ "Yten Guariño», que lleva efectivamente la tilde de la nasal, palatal sonora. ${ }^{15}$ Terminada la relación, y de la misma mano, sigue la famosa rúbrica (h. 14r-h. 14v) que tomamos prestada para la titulación de nuestro trabajo: "Los quales dichos libros suso traydos y viejos y algunos rotos [...]», y a continuación sigue la de sus [signación] "libros de leyes» (h. 14v-h. 15r); rematan el documento (h. 15v-16r), de otra mano coetánea, dos rúbricas finales, una para la donación a su hijo Francisco de «los quales dichos libros de leyes [...]»y una postrera, que cierra el legajo y el contenido general de todo el «Inventario»: «los quales dichos bienes de suso contenido [...]».

No da más de sí el cotejo del documento, que, en sus rasgos generales, coincide con lo transcrito en su día y estudiado después, ${ }^{16}$ nada cambia, pues, nuestras conclusiones a este respecto (identificaciones, organización, estadísticas, etc.) y sólo queríamos corregir una imprecisión en una de las notas correspondientes al $n^{\circ}$ [37] «Yten el libro de Axedrez» — sin nada que ver directamente, desde luego, con el título y la obra-, pues decíamos (y perdón: porque lo hacíamos fiados de la memoria y sin comprobar directamente) que el ejemplar «de la Biblioteca Universitaria de Salamanca, [...] también carece de dos hojas de la signatura G, con proble-

14.- Recordamos que la tasación y copia se inicia el día 8 de abril y no termina hasta el 21 de junio, pudo ocurrir (y así creemos que sucedió) que uno de los amanuenses comenzara el inicio del vuelto de la hoja con la indicación de lo que iba a contener: «libros de romance» y se suspendiera la tarea; cuando se continuó otro de ellos fue quien escribió la relación de los títulos. Minucias paleográficas de poca monta, pero minucias que se deben señalar.

15.- Cf. V. Infantes, «Los libros», cit., pp. 9-10.

16.- Valga recordar lo que sugerimos en 1998 sobre las primeras identificaciones superficiales de los «libros de romance», que eran obra de la "Redacción» de la Revista de Filología Española, "tal y como se indica en un epígrafe titulado "NOTAS DE LA REDACCIÓN», no sabemos si interpretar la aposición como la $1^{\text {a }}$ o la $3^{\text {a }}$ acepción del DRAE, Madrid: Real Academia Española, 1984, 20 ed., II, p. 1157, lo que Gilman denomina de "los editores de la RFE», y aunque esto es así, preferimos mencionar al autor del artículo como cita. (De hecho parece quedar claro que Valle Lersundi aporta los documentos con su transcripción, pp. 366-383, y que la "Redacción» de la revista añade las «Notas de la Redacción» con las identificaciones, pp. 384-388, al igual que al comienzo del artículo añade una única nota entre corchetes, con la mención de «N[ota]. de la $R$ [edacción].», p. 383, justificando la publicación de los documentos; cuatro años antes había sucedido lo mismo, el primer artículo de Valle Lersundi donde se recogía la «Probanza de hidalguía de sangre» de nuestro autor, «Documentos» [cit.], se acompaña con un breve texto inicial donde se justifica la aparición del testimonio firmado por «La Redacción».», vid. V. Infantes, «Los libros», cit., p. 12. 
mas de la defensa india del Rey", y no, no se trata allí de la defensa india, sino de diferentes problemas de finales con la Dama y el " iejo». ${ }^{17}$

La segunda espina no la hemos desclavado todavía, aunque los designios de la investigación son inescrutables. Ya habíamos señalado que en los años setenta parece que todavía existían algunos ejemplares provenientes de la Biblioteca de Fernando de Rojas en poder de Don Fernando del Valle Lersundi; libros que no pudo ver Gilman —o que, al menos, no dejó constancia escrita de su posible consulta- y sobre los que corría la tradición oral de saber si verdaderamente eran del Bachiller o, tal vez, ediciones antiguas de la época de Rojas (entre finales del siglo XV y 1541), aunque no necesariamente pertenecientes a su biblioteca personal. También se sugería, como dato que avalaba la mitografía bibliófila, que se encontraban en "muy mal estado" —recuérdese la coda testamentaria de «viejos y algunos rotos»-, así como que estaban «dañados por el agua», al haber estado en un sótano durante muchos años. Nadie ha publicado (hasta donde llegan nuestras pesquisas) una constatación de la existencia actual de alguno de estos ejemplares. ${ }^{18}$ La muerte de Don Fernando del Valle cerró las especulaciones sobre los maltrechos volúmenes y sólo el trabajo de Gilman a comienzos de los años setenta volvió a sacar el tema de la biblioteca de Fernando de Rojas - aunque al hilo de otros intereses socioculturales más ambiciosos-y casi treinta años después nosotros mismos. Hoy por hoy no tenemos en las manos ninguno de estos «libros de romance», aunque es posible que pronto contemos con la verificación - sobre la que no ha lugar extenderse ahora- de que alguno de los items del «Inventario» todavía existía en vida de Don Fernando del Valle Lersundi, por más que su paradero actual —si es que han sobrevivido a las vicisitudes de su larga existencia - sea (a día de hoy) una incógnita. Pero si no conocemos ninguno de los «libros de romance», sí sabemos, a cambio, del paradero de uno de sus «libros de leyes»; y con una grata sorpresa que justifica de largo el paréntesis de nuestro título

Dijimos en 1998:

No es nuestro interés (de momento) continuar con los infolios de Derecho de nuestro Bachiller, centrados en sus lecturas literarias, aunque desde luego habría que tenerlos (muy) en cuenta cuando se trabaja con inventarios

17.- Vid. Joaquín Pérez de Arriaga, El incunable de Lucena. Primer arte de ajedrez moderno, Madrid, Polifemo, 1997, I, pp. 576-577, el segundo volumen es el facsímile; se puede añadir Ricardo Calvo, Lucena; la evasión en ajedrez del converso Calisto, Ciudad Real, Perea Ediciones, 1997, autor que sugiere la identificación de Luis Ramírez de Lucena, autor de la Repetición de amores que antecede al Arte de axedrez, como un retrato del Calisto de la Celestina. (Ambos estudios no habían aparecido cuando entregamos nuestro trabajo.)

18.- Aunque conservamos una significativa carta de un hispanista dedicado a tareas celestinescas, donde nos cuenta (confidencialmente) una serie de datos sobre este legado, que quizás en algún momento tengamos que contar por escrito. 
de depósitos particulares, pues son al fin y al cabo parte de la propia biblioteca y especialmente en este caso; la transcripción está en Valle, ${ }^{19}$ [...] y una (primera, pero suficiente) identificación de Luis G. de Valdeavellano, en Gilman, como «Apéndice Iv. Los libros de Leyes del Bachiller». ${ }^{20}$

En esta segunda lista de libros, que recibe en herencia su hijo Francisco, se encuentra en el $n^{\circ}$ [34] "Yten Cortes de To[ledo] del año de veynte y cinco"; ${ }^{21}$ una identificación evidente nos lleva a las famosas Cortes toledanas de 1525 (con algunas sombras del Lazarillo hoy tan olvidadas...), que imprimió Alonso de Melgar, en Burgos, en febrero del año siguiente. La exhaustiva descripción de Mercedes Fernández Valladares nos ahorra perdernos en pormenores bibliográficos ${ }^{22}$ aunque sí recabamos la atención ante un problema derivado de la identificación de las entradas de los inventarios (tal y como nos pasó con los de "romance») y volvemos a (auto)citarnos y a recordar lo que ya dijimos entonces, que viene muy al caso de lo que contaremos más tarde. ${ }^{23}$

Una cuestión importante queremos indicar de antemano. Lo habitual en este tipo de documento es copiar exclusivamente los datos más elementales de la identific ción del libro, generalmente los indicados en la portada del mismo, sin entrar en ningún tipo de precisión específica; de ahí el interés nuestro en suponer una transcripción más o menos exacta de los datos allí recogidos e intentar comprender las variantes y lecciones diferentes, en ocasiones (casi) como si se tratara de un problema de crítica textual; asunto que se complica si añadimos nuestro convencimiento de que en muchos casos estamos ante una transcripción al dictado, lo que añade (nuevas) lecciones y variantes a una copia no de por sí especialmente cuidadosa. Esta tipología de problemas: pericopas, homografías, homofonías, etc., no producen ningún problema insalvable en la identificación de las obras, pero sí muy específicos en la identificación de las ediciones concretas, que en numerosos items son las únicas posibilidades de

19.- Vid. F. del Valle Lersundi, «Testamento», cit., pp. 382-383.

20.- Vid. S. Gilman, La España de Fernando de Rojas, cit., pp. 507-514.

21.- Puede leerse en F. del Valle Lersundi, «Testamento, cit., p. 383; en el documento original se encuentra en la h. $15 \mathrm{r}$.

22.- Vid. Mercedes Fernández Valladares, La imprenta en Burgos (1501-1600), Madrid, Arco/ Libros, 2005, I, n ${ }^{\circ} 176$ y n$^{\circ} 177$, que diferencia variantes para las dos tiradas, con abundantes ejemplares conservados de ambas salidas editoriales.

23.- V. Infantes, «Testamento», cit., pp. 12-13. 
decidirse por una u otra posible impresión. De ahí que insistamos, en ocasiones de una forma minuciosa e impertinente, en detalles tan menudos y tan nimios como reveladores. Después de darle muchas vueltas al asunto, rechazamos en conjunto que se tomaran los datos de las encuadernaciones, y es una pena, pues en la mayoría de las transcripciones vendrían francamente bien para algunos libros que se resisten a la identificación inmediata; ¿no era la práctica habitual? en el caso de que las rotulaciones lo permitieran, sobre todo dado el estado general que deberían tener los libros de nuestro Bachiller, pero en algún caso concreto no desdeñamos esta posibilidad. No excluimos, a cambio, la posibilidad de que bien en la cara interna de la guarda de vuelta de la encuadernación, habitualmente en blanco sobre el papelón utilizado para reforzar la tapa, o en la primera hoja, impresa (= la portada) o en blanco en alguna ocasión, existiera alguna rúbrica (lógicamente manuscrita) del propio Rojas que señalara abreviadamente el título del libro según la costumbre de tantos poseedores; si así fuera, al menos en algún caso y tampoco es del todo desdeñable la hipótesis, lo que se copia en la transcripción sería, precisamente, la forma de nombrar el libro por parte de Rojas (o de quien allí lo hubiera escrito), lo que podría explicar algún olvido y ciertas alteraciones.

La edición ostenta en la portada: Las cortes de Toledo. Del año de mil y quinientos y veynte y cinco años (Burgos, Alonso de Melgar, 1526; fol., gót., 22 hs., sgnts.: avj-cvj+diiij) y la identificación es evidente, aunque debemos precisar - en aras de una mayor claridad bibliográfica - que existen dos ediciones con pequeñas diferencias, reseñadas concienzudamente por Fernández Valladares; nada varía en ello para saber que Fernando de Rojas tuvo una de ellas (y para la identificación y para la lectura del texto bien poco importa) y que además es imposible — dado el tipo de sintética información que se recoge en un inventario- que se pudiera señalar la fecha real del impreso que sólo se indica del colofón, situado (claro está) en h. 22r: «aca $=/$ baronse a veynte y dos dias del mes de / Hebrero de mil \& quinientos \& ve=/ ynte \& seys Años.». Es decir y como habíamos supuesto para otros muchos casos: el escribano copia (sintéticamente) los datos elementales que se leen (o le dictan) en la portada que tiene delante. En este caso la tarea de identificación no supone ninguna contrariedad entre lo recogido en el "Inventario» - tomado evidentemente de la portada - y la realidad del ejemplar, pues a la postre se trata (prácticamente) de la misma obra, aunque no sea de la misma tirada editorial. 
La diferencia es que este libro que poseyó Fernando de Rojas ha llegado hasta nosotros. ${ }^{24}$ En un más que aceptable estado de conservación, sin encuadernar, es decir "en rama", con evidentes señales de uso y lectura (bordes doblados, manchas en algunas hojas, arrugas del papel, etc.); nos pareció nada más tenerlo en las manos que se trataba de un impreso de carácter "práctico", de lectura habitual como cuaderno legislativo - y así se han titulado alguno de los primeros impresos sobre la materia: Cuaderno de alcabalas, de leyes, de ordenanzas, etc.-, y que por su escasa extensión, andaba probablemente más por encima de una mesa, a mano para su consulta, que verticalmente situado en una estantería. Se trata de un libro que recoge las disposiciones legales emanadas de las Cortes toledanas y parece (ciertamente) lógica su posesión por parte de un jurista, de hecho - es obvio recordarlo- figura en el inventario de su biblioteca; estamos, pues, en la geografía toledana de nuestro autor, ${ }^{25}$ ante un libro de su profesión y con un tema de enorme interés para un abogado y personaje público como era Rojas. Pero, además, con una (decíamos) «grata sorpresa»: lleva anotaciones marginales en algunas páginas en letra claramente coetánea a la edición, que no tenemos más remedio que suponer que (sólo) son de su dueño: Fernando de Rojas. Se nos desvela así el lector y propietario de este ejemplar a través de una caligrafía que observamos (atónitos y maravillados) por primera vez.

Desde hace algunos años se ha empezado a conceder la importancia que merece a las anotaciones manuscritas de los libros, ${ }^{26}$ hasta el punto

24.- Los datos de procedencia irrefutables que manejamos en la ubicación actual del ejemplar, y que agradecemos en toda su valía por escrito, nos aseguran que se trata, efectivamente, de un libro perteneciente a la biblioteca personal de Fernando de Rojas, garantizado, además, por la coincidencia entre asiento del inventario y volumen.

25.- Aprovechamos la nota para citar un dato que siempre nos llamó la atención, tenga o no relación con nuestro Fernando de Rojas, pues en Perdón general (s. 1., s. i., s. a., pero Alcalá de Henares, Arnao Guillén de Brocar, 1522; fol., gót., 6 hs., sgnts.; Aiiij+2), que Carlos I concede el 28 de octubre de 1522 en Valladolid después de la revuelta comunera, figuran entre la lista de aquellos que «no ayan de gozar ni gozen» del mismo, un "Francisco de rojas, vezino de toledo" y un "Fernando de rojas vezino de toledo» [h. 4r] y, precisamente, el segundo de ellos aparece subrayado a mano en el ejemplar de la Biblioteca Nacional de España (R/12650); vid. Julián Martín Abad, La imprenta en Alcalá de Henares (1502-1600), Madrid, Arco/Libros, 1991, I, n 101 y edición facsímile en Ramillete de noticias del Emperador Carlos V. Homenaje a La Arcadia, ed. El Aprendiz de Bibliófilo (= Carlos Romero de Lecea), Madrid, La Arcadia, 1959, $\mathrm{n}^{\circ}$ II, $\mathrm{s} / \mathrm{p}$.

26.- Pueden citarse, desafortunadamente con escasa atención a nuestra cultura, Roger E. Stoddard, Marks in Books, Illustrated and Explained, Cambrigde (Mass.), Harvard University Press, 1985; Robin C. Alston., Books with Manuscript. A Short Title Catalogue of Books with Manuscript Notes in the British Library. Including Books with Manuscript Additions, Proofsheets, Illustrations, Corrections. With Indexes of Owners and Books with Authorial Annotations, London, The British Library, 1994; The Margins of the Text, ed. David C. Greetham, Ann Arbor, University of Michigan Press, 1997; The Rosenthal Collection of Printed Books and Manuscripts Annotations, New Haven, Yale University Press, 1997; Le Livre Annoté, [monográfico] Revue de la Bibliothèque Nationale de France, 2 (1999); Heather P. Jackson, Marginalia. Readers wrinting in books, New Haven, Yale 
de entender como otro texto - a veces más importante que el impresola presencia de estas señales de lectura personal; valga recordar que precisamente la Celestina tiene un señero testimonio, en el (hasta ahora) único ejemplar completo de la edición de la Tragicomedia de Zaragoza, Jorge Coci, 1507, anotada por dos juristas, que ha desentrañado concienzudamente Nieves Baranda. ${ }^{27}$ Miguel Servet comenta a Dioscórides ${ }^{28}$, Francisco de Quevedo apostilla la Retórica de Aristóteles ${ }^{29}$, Fernando de Rojas anota la lectura de un texto legal de especial significación en aquellos momentos del establecimiento en España de Carlos I.

Los orígenes del ejemplar nos inclinan a pensar necesariamente en la letra de Fernando de Rojas, en la escritura personal del Bachiller salmantino, con los rasgos silenciosos de una larga memoria escrita que ha llegado por fin hasta nuestros días. Desgraciadamente no conservamos testimonios manuscritos - y mucho menos pruebas de escritura- de Fernando de Rojas, lo que imposibilita una comparación caligráfica de autoría, aunque quizá estas marginalia sirvan ahora como verificación si aparece algún día un texto que merezca el peritaje. Las primeras sugerencias sobre el "Manuscrito de Palacio", como un posible manuscrito ológrafo ${ }^{30}$, están hoy ampliamente desechadas ${ }^{31}$ y los documentos conservados en el

University Press, 2001; The Reader Revealed, ed. Sabrina Alcorn Baron, Washington, The Folger Shakespeare Library, 2001, que recordamos en el título; Nel mondo delle postille: i libri a stampa con note manoscritte. Una racolta di studi, ed. Edoardo Barbieri, Milano, CUSL, 2002; etc.

27.- Nieves Baranda, "Leyendo «frontezicas de filosophía». Marginalia a un ejemplar de la Tragicomedia de Calisto y Melibea (Zaragoza, 1507)", en Actas del Simposio Internacional 1502-2002: Five Hundred Years of Fernando de Rojas' Tragicomedia de Calisto y Melibea (18-19 de octubre de 2002, Departamento de Español y Portugués, Indiana University, Bloomington), ed. Juan Carlos Conde, New York, The Hispanic Seminary of Medieval Studies, 2007, pp. 269-310

28.- Vid. Miguel Servet, editor de Dioscórides, ed. Francisco Javier González Echevarría, Villanueva de Sijena, Instituto de Estudios Sijenenses, 1997.

29.- Vid. Anotaciones de Quevedo a la "Retórica» de Aristóteles, ed. Ma Luisa López Grigera, Salamanca, Gráficas Cervantes, 1998.

30.- Vid. los trabajos de Charles B. Faulhaber al hilo de su descubrimiento, "Celestina de Palacio: Madrid, Biblioteca de Palacio Ms 1520», Celestinesca, 14, 2 (1990), pp. 3-39; "Celestina de Palacio: Rojas Holograph Manuscript?», Celestinesca, 15, 1 (1991), pp. 3-52 y «Ms 1520 de la Biblioteca de Palacio. De los «papeles del antiguo auctor» a la Comedia de Calisto y Melibea: Fernando de Rojas trabaja su fuente», en Actas do IV Congresso da Associação Hispânica de Literatura Medieval (Lisboa, 1-5 Outubro 1991), eds. Aires A. Nascimento y Cristina Almeida Ribero, Lisboa, Edições Cosmos, 1993, II, pp. 283-287

31.- Así lo han puesto de relieve, desde distintos intereses y diferentes ópticas, Ian Michael, "La Celestina de Palacio: el redescubrimiento del MS. II-1520 (sign. ant. 2.A.4) y su procedencia segoviana, Revista de Literatura Medieval, III (1991), pp. 149-161; Juan Carlos Conde, «El manuscrito II-1520 de la Biblioteca de Palacio: un nuevo testimonio del Diálogo de Vita Beata de Juan de Lucena», La Corónica, 21, 2 (1992-1993), pp. 34-57; Patrizia Botta, «La Celestina de Palacio en sus aspectos materiales», Boletín de la Real Academia Española, 73 (1993), pp. 25-50 y 347-366; Michel Garcia, "Consideraciones sobre 'Celestina' de Palacio», Celestinesca, 18, 1 (1994), pp. 3-16; Juan Carlos Conde, El manuscrito II-1520 de Palacio y la Celestina: balance y estado de la cuestión», en Cinco siglos de Celestina: aportaciones interpretativas, ed. Rafael Beltrán 
Archivo Municipal de Talavera de la Reina, que tanto nos han ayudado a entender algunos avatares de su biografía, ${ }^{32}$ no contienen siquiera una fi ma de nuestro autor..$^{33}$ Quedan corroborar algunas incógnitas pendientes, analizar al detalle los escuetos testimonios y dar vueltas a otras sugerencias todavía en mantillas documentales. Pero de aquellos libros que «tuvo el Bachiller Fernando de Rojas, nombrado autor de la obra llamada Celestina", uno, al menos, ha sobrevivido, y en él, permanece un testimonio escrito fosilizado en sus márgenes: la sombra caligráfica que nos desvela el lector que lo tuvo entre sus manos.

y José Luis Canet, Valencia, Universidad de Valencia, 1997, pp. 161-185; Francisco Lobera, "Sobre historia, texto y ecdótica, alrededor del Manuscrito de Palacio», en La Celestina, v centenario (1499-1999). Actas del Congreso Internacional (Salamanca, Talavera de la Reina, Toledo, La Puebla de Montalbán, 27 de septiembre-1 de octubre de 1999), eds. Felipe B. Pedraza Jiménez, Rafael González Cañal y Gema Gómez Rubio, Cuenca, Universidad de Castilla-La Mancha, 2001, pp. 79-96; Juan Carlos Conde, «1989-1999: diez años de la Celestina manuscrita de Palacio», en Los orígenes del español y los grandes textos medievales: "Mí Cid», "Buen amor» y "Celestina", Madrid, CSIC, 2001, ed. Manuel Criado de Val, pp. 265-288 y Mª Luisa López-Vidriero, «La «Celestina de Palacio»: un origen no tan incierto", en La Celestina 1499-1999. Selected Papers from Internacional Congress in Commemoration of the Quincentennial Anniversary of La Celestina. New York, November 17-19, 1999, eds. Ottavio DiCamilo y John O’Neill, New York: Hispanic Seminary of Medieval Studies, 2005, pp. 125-151, entre otros.

32.- Vid. los recogidos por Inés Valverde, "Fernando de Rojas: alcalde y hombre de letras», en Talavera en el tiempo. Primer Ciclo Conferencias'92, Talavera de la Reina, Ayuntamiento de Talavera de la Reina, 1992, pp. 153-171.

33.- Ya parecía quedar claro en los resúmenes (y transcripciones) de Inés Valverde, cit., supra, pero nos lo confirma Don Rafael Gómez Díaz, su actual Director, a quien agradecemos sinceramente sus aclaraciones. 


\section{Bibliografía}

Alston, Robin C., Books with Manuscript. A Short Title Catalogue of Books with Manuscript Notes in the British Library. Including Books with Manuscript Additions, Proofsheets, Illustrations, Corrections. With Indexes of Owners and Books with Authorial Annotations, London, The British Library, 1994.

Baranda, Nieves, "Leyendo "frontezicas de filosophía». Marginalia a un ejemplar de la Tragicomedia de Calisto y Melibea (Zaragoza, 1507)", en Actas del Simposio Internacional 1502-2002: Five Hundred Years of Fernando de Rojas' Tragicomedia de Calisto y Melibea (18-19 de octubre de 2002, Departamento de Español y Portugués, Indiana University, Bloomington), ed. Juan Carlos Conde, New York, The Hispanic Seminary of Medieval Studies, 2007, pp. 269-310.

BotTA, Patrizia, "La Celestina de Palacio en sus aspectos materiales», Boletín de la Real Academia Española, 73 (1993), pp. 25-50 y 347-366.

Briouet, Charles M., Les filigranes. Dictionnaire historique des marques du papier, Leipzig, Karl W. Hiersemann, 1921², 4 vols. [= Hildesheim, Georg Olms, 1991].

Calvo, Ricardo, Lucena; la evasión en ajedrez del converso Calisto, Ciudad Real, Perea Ediciones, 1997.

Conde, Juan Carlos, "El manuscrito II-1520 de la Biblioteca de Palacio: un nuevo testimonio del Diálogo de Vita Beata de Juan de Lucena", La Corónica, 21, 2 (1992-1993), pp. 34-57.

-, El manuscrito II-1520 de Palacio y la Celestina: balance y estado de la cuestión", en Cinco siglos de Celestina: aportaciones interpretativas, ed. Rafael Beltrán y José Luis Canet, Valencia, Universidad de Valencia, 1997, pp. 161-185.

Faulhaber, Charles, "Celestina de Palacio: Madrid, Biblioteca de Palacio Ms 1520", Celestinesca, 14.2 (1990), pp. 3-39.

—, "Celestina de Palacio: Rojas Holograph Manuscript?», Celestinesca, 15.1 (1991), pp. 3-52.

—, "Ms 1520 de la Biblioteca de Palacio. De los «papeles del antiguo auctor» a la Comedia de Calisto y Melibea: Fernando de Rojas trabaja su fuente», en Actas do IV Congresso da Associação Hispânica de Literatura Medieval (Lisboa, 1-5 Outubro 1991), eds. Aires A. Nascimento y Cristina Almeida Ribero, Lisboa, Edições Cosmos, 1993, II, pp. 283-287.

Fernández Valladares, Mercedes, La imprenta en Burgos (1501-1600), Madrid, Arco/Libros, 2005, 2 ts.

Garcia, Michel, "Consideraciones sobre 'Celestina' de Palacio", Celestinesca, 18, 1 (1994), pp. 3-16.

Gayoso Carreira, Gonzalo, Historia del papel en España, Lugo, Diputación Provincial, 1994, 3 ts.

Gilman, Stephen, La España de Fernando de Rojas. Panorama intelectual y social de La Celestina [1972], Madrid, Taurus, 1972. 
INFANTES, Víctor, «Los libros «traydos y viejos y algunos rotos» que tuvo el Bachiller Fernando de Rojas, nombrado autor de la obra llamada Celestina», Bulletin Hispanique [Lisant et Lecteurs en Espagne XV'-XIX siécle], 100.2 (1998), pp. 7-51.

- "El laberinto cronológico y editorial de las primitivas impresiones de Celestina (1497-1514). Con una Marginalia bibliographica al cabo", en Actas del Simposio Internacional 1502-2002: Five Hundred Years of Fernando de Rojas' Tragicomedia de Calisto y Melibea (18-19 de octubre de 2002, Departamento de Español y Portugués, Indiana University, Bloomington), ed. Juan Carlos Conde, New York, Hispanic Seminary of Medieval Studies, 2007, pp. 3-87.

Jackson, Heather P., Marginalia. Readers Wrinting in Books, New Haven, Yale University Press, 2001.

EL JARDÍN de Melibea, Burgos, Sociedad Estatal para la Conmemoración de los Centenarios de Felipe in y Carlos v, 2000.

LE LIVRE annoté, [monográfico] Revue de la Bibliothèque Nationale de France, 2 (1999)

Lobera, Francisco, "Sobre historia, texto y ecdótica, alrededor del Manuscrito de Palacio", en La Celestina, V centenario (1499-1999). Actas del Congreso Internacional (Salamanca, Talavera de la Reina, Toledo, La Puebla de Montalbán, 27 de septiembre-1 de octubre de 1999), eds. Felipe B. Pedraza Jiménez, Rafael González Cañal y Gema Gómez Rubio, Cuenca, Universidad de Castilla-La Mancha, 2001, pp. 79-96.

López-Vidriero, $M^{a}$ Luisa, "La "Celestina de Palacio»: un origen no tan incierto", en La Celestina 1499-1999. Selected Papers from Internacional Congress in Commemoration of the Quincentennial Anniversary of La Celestina. New York, November 17-19, 1999, eds. Ottavio DiCamilo y John O'Neill, New York: Hispanic Seminary of Medieval Studies, 2005, pp. 125-151.

THE MARGINS of the Text, ed. David C. Greetham, Ann Arbor, University of Michigan Press, 1997.

MarTín Abad, Julián, La imprenta en Alcalá de Henares (1502-1600), Madrid, Arco/Libros, 1991, 3 ts.

Michael, Ian, «La Celestina de Palacio: el redescubrimiento del MS. II-1520 (sign. ant. 2.A.4) y su procedencia segoviana», Revista de Literatura Medieval, III (1991), pp. 149-161.

NEL MONDO delle postille: $i$ libri a stampa con note manoscritte. Una racolta di studi, ed. Edoardo Barbieri, Milano, CUSL, 2002.

Pérez de Arriaga, Joaquín, El incunable de Lucena. Primer arte de ajedrez moderno, Madrid, Polifemo, 1997, 2 vols.

RAMILLETE de noticias del Emperador Carlos V. Homenaje a La Arcadia, ed. El Aprendiz de Bibliófilo (= Carlos Romero de Lecea), Madrid, La Arcadia, 1959. 
THE READER Revealed, ed. Sabrina Alcorn Baron, Washington, The Folger Shakespeare Library, 2001.

THE ROSENTHAL Collection of Printed Books and Manuscripts Annotations, New Haven, Yale University Press, 1997.

StodDard, Roger E., Marks in Books, Illustrated and Explained, Cambridge (Mass.), Harvard University Press, 1985.

Valls I SUBIRÀ, Oriol, La historia del papel en España, Madrid, Empresa Nacional de Celulosas, 1978-1982, 3 ts.

Valle LeRsund, Fernando del, «Documentos referentes a Fernando de Rojas», Revista de Filología Española, XI (1925), pp. 385-396.

-, "Testamento de Fernando de Rojas, autor de La Celestina», Revista de Filología Española, XVI (1929), pp. 365-388.

VALVERDE, Inés, "Fernando de Rojas: alcalde y hombre de letras», en Talavera en el tiempo. Primer Ciclo Conferencias'92, Talavera de la Reina, Ayuntamiento de Talavera de la Reina, 1992, pp. 153-171.

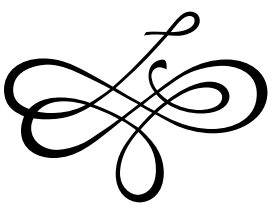




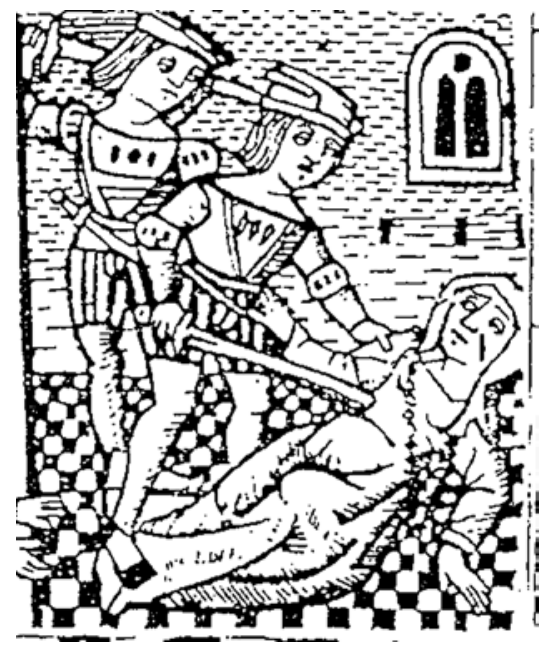


INFANTES, Víctor, "Fernando de Rojas: el lector desvelado (en su caligrafía). De nuevo sobre el 'Inventario' de sus libros", Celestinesca 31 (2007), pp. 103-118.

\section{RESUMEN}

Partiendo de un trabajo publicado en 1998 (Bulletin Hispanique, 100, 2 (1998), pp. 7-51), se ofrece una revisión sobre algunos aspectos de los documentos que recogen el «Testamento» y el «Inventario» de los libros de Fernando de Rojas; asimismo se ofrece la identificación de un ejemplar proveniente de su biblioteca personal, que presenta anotaciones marginales manuscritas de lectura y que muy probablemente pertenezcan al escritor.

PALABRAS CLAVE: «Testamento» e "Inventario» de libros de Fernando de Rojas, biblioteca del escritor, anotaciones manuscritas.

\section{ABSTRACT}

Following an essay of 1998 (Bulletin Hispanique, 100, 2 (1998), pp. 7-51) a review of some aspects of Fernando de Rojas' will and book inventory is made. At the same time it has been possible to identify a book from his personal library which has reader's manuscript marginalia probably due to the writer's hand.

KEY WORDS: Will, book inventory of Fernando de Rojas, writer library, book marginalia.

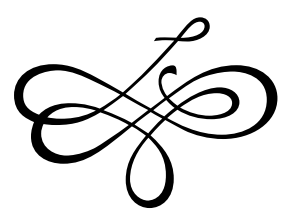

